\title{
Characteristics and antithrombotic treatment patterns of patients with concomitant coronary artery disease and atrial fibrillation from Thailand's COOL-AF registry
}

Arjbordin Winijkul, Pontawee Kaewkumdee, Ahthit Yindeengam and Rungroj Krittayaphong*

\begin{abstract}
Background: Concomitant coronary artery disease (CAD) and atrial fibrillation (AF) are common in clinical practice. The aim of this study was to investigate the characteristics and antithrombotic treatment patterns of patients with concomitant CAD and AF from the COhort of antithrombotic use and Optimal INR Level in patients with non-valvular atrial fibrillation in Thailand (COOL-AF Thailand) registry.
\end{abstract}

Methods: Registry enrollment criteria included patients aged $\geq 18$ years who were diagnosed with AF for any duration at any of 27 public hospitals located across Thailand during 2014-2017. The That Clinical Trials Registry study registration number is TCTR20160113002. Statistical comparisons of characteristics and treatment strategies were performed between patients with and without CAD.

Results: Of a total of 3461 AF patients, 557 had concomitant CAD (16.1\%). Patients with concomitant CAD and AF were significantly older, more likely to be male, had more comorbidities, and had more cardiovascular implantable electronic devices. History of stroke/transient ischemic attack and prior bleeding was not significantly different between groups. $\mathrm{CHA}_{2} \mathrm{DS}_{2}$-VASC score and HAS-BLED score were both higher in patients with CAD than in patients without CAD (4.17 vs. $2.78, p<0.001$, and 2.01 vs. 1.45, $p<0.001$, respectively). Utilization of oral anticoagulant was less in patients with CAD $(76.0 \%$ vs. $84.3 \%, p<0.001)$. Concomitant use of antiplatelet was found to be a major cause of oral anticoagulant (OAC) underutilization. Specifically, the rate of OAC prescription was $95.9 \%$ in patients without antiplatelet, and $43.7 \%$ in patients with antiplatelet. Among patients with CAD who were on OAC, the rate of concomitant antiplatelet prescription was still high. In this group, 63\% of patients were on triple therapy when percutaneous coronary intervention (PCl) with drug eluting stent was performed within 1 year, and 32.2\% of patients without prior $\mathrm{PCl}$ or acute coronary syndrome were taking at least one antiplatelet with OAC.

Conclusion: Among patients with concomitant $C A D$ and $A F$, physicians were reluctant to discontinue antiplatelet. The use of antiplatelet discourages physicians from prescribing OAC. Underutilization of OAC may increase the risk of ischemic stroke, and an inappropriate combination of OAC and antiplatelet may increase the risk of bleeding.

Trial registration The trial has been registered with the Thai Clinical Trials Registry (TCTR) which complied with WHO International Clinical Trials Registry Platform dataset. The Registration Number is TCTR20160113002 (05/01/2016).

\footnotetext{
*Correspondence: rungroj.kri@mahidol.ac.th

Division of Cardiology, Department of Medicine, Faculty of Medicine

Siriraj Hospital, Mahidol University, 2 Wanglang Road, Bangkoknoi,

Bangkok 10700, Thailand
}

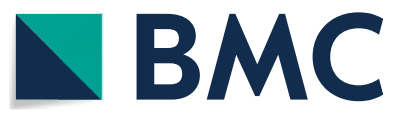

(c) The Author(s) 2021. This article is licensed under a Creative Commons Attribution 4.0 International License, which permits use, sharing, adaptation, distribution and reproduction in any medium or format, as long as you give appropriate credit to the original author(s) and the source, provide a link to the Creative Commons licence, and indicate if changes were made. The images or other third party material in this article are included in the article's Creative Commons licence, unless indicated otherwise in a credit line to the material. If material is not included in the article's Creative Commons licence and your intended use is not permitted by statutory regulation or exceeds the permitted use, you will need to obtain permission directly from the copyright holder. To view a copy of this licence, visit http://creativecommons.org/licenses/by/4.0/. The Creative Commons Public Domain Dedication waiver (http://creativecommons.org/publicdomain/zero/1.0/) applies to the data made available in this article, unless otherwise stated in a credit line to the data. 
Keywords: Atrial fibrillation, Coronary artery disease, Multicenter registry, Anticoagulant, Antiplatelet

\section{Introduction}

Coronary artery disease (CAD) and atrial fibrillation (AF) are both common cardiovascular diseases. These two conditions share common risk factors, such as older age, hypertension (HT), diabetes mellitus (DM), and smoking [1]. Therefore, coexistence of these two conditions is common in routine clinical practice.

Management of patients with concomitant CAD and $\mathrm{AF}$ is a challenge. Management of AF requires oral anticoagulant $(\mathrm{OAC})$ for long-term prevention of stroke and systemic embolism (SSE) [1-3]. Certain spectra of CAD require one or two different antiplatelets to prevent acute coronary events [4]. When anticoagulant and antiplatelet are used together, the risk of bleeding markedly increases [5]. Recent studies focused upon and recent guidelines recommend optimized use of antithrombotic regimens in this patient population [3, 4]. In general, single antiplatelet instead of two agents along with $\mathrm{OAC}$ might be reasonable for patients with AF who recently received a coronary stent [6-10], CAD patients who have no recent acute coronary syndrome (ACS) or coronary interventions might be able to discontinue the use of antiplatelet if they already have an indication for OAC $[11,12]$. However, current guidelines recommend selecting the antithrombotic regimen by weighing thrombotic risk against bleeding risk [13]. Some scoring systems have been proposed and validated for use in predicting bleeding in patients after coronary intervention $[14,15]$. The duration of antithrombotic combination and choice of antiplatelet may influence the risk of bleeding after coronary intervention [16]. Although several thrombotic and bleeding risk scores are available in real-world clinical practice, physicians also attempt to find a balance between thrombotic risk and bleeding risk using subjective unmeasurable factors or by being more concerned about one of the two risks more than the other.

The COOL-AF Thailand registry is a national multicenter prospective cohort with the primary aim of identifying the optimal range of international normalized ratio (INR) in Thai AF patients. The objective of the present study was to investigate the characteristics and antithrombotic treatment patterns of patients with concomitant CAD and AF from Thailand's COOL-AF registry.

\section{Methods}

The study protocol was approved by the institutional review boards of all participating hospitals. The protocol for this registry was approved by the Central Research Ethics Committee (CREC) for Research in Human Subjects of the Ministry of Public Health, Thailand. Written informed consent was obtained from all included patients. Baseline data of patients in the COOL-AF Thailand registry were analyzed. The registry enrollment criteria were patients aged 18 years or older who were diagnosed with AF for any duration at any one of 27 public hospitals in Thailand during 20142017 (Thai Clinical Trials Registry study Identification Number TCTR20160113002, 05/01/2016). Key exclusion criteria were patients with rheumatic mitral stenosis, prosthetic heart valve or other moderate to severe valvular diseases, ischemic stroke within 3 months, and AF secondary to reversible causes. The primary objective of the COOF-AF registry was to identify an optimal INR for stroke prevention in Thai population diagnosed with AF. The baseline characteristics of all patients enrolled in the registry were recently published [17]. After the informed consent process, the investigators recorded data from the medical record and from patient interview into both a specially designed case record form and a web-based system. In this registry, patients were labeled as having had a history of significant CAD if patients had (1) a history of angina pectoris, (2) a history of myocardial infarction (MI) or unstable angina, (3) a history of previous percutaneous coronary intervention (PCI), or (4) a history of previous coronary artery bypass graft (CABG) surgery.

Since different spectra of CAD require a different recommended antiplatelet regimen, patients with CAD were further subclassified into (1) patients who recently (within 1 year) received a drug-eluting stent, (2) patients who received a coronary artery stent longer than 1 year previously, (3) patients who experienced acute coronary syndrome (ACS) within 1 year, but never received a stent, or (4) patients with CAD without history of ACS or receiving a stent.

According to recent guidelines, oral anticoagulant is a class I recommendation when the $\mathrm{CHA}_{2} \mathrm{DS}_{2}$-VASc score is 2 or more in men, and 3 or more in women. Therefore, in this article the term 'non-gender $\mathrm{CHA}_{2} \mathrm{DS}_{2}$-VASc score' was used to indicate treatment threshold (non-gender $\mathrm{CHA}_{2} \mathrm{DS}_{2}$-VASc score of 2 or more as class I recommendation). 
The primary objective of this article was to study patterns of antithrombotic regimens among patients with $\mathrm{AF}$ among different spectra of coexisting CAD.

\section{Statistical analysis}

Baseline demographic and clinical data were interpreted and described using descriptive statistics. Continuous data are presented as mean \pm standard deviation, and categorical data are shown as number and percentage. Comparison was made between patients with and without CAD. Student's $t$-test was used to compare continuous data, and chi-square test was used to compare categorical data. Univariate and multivariate logistic regression analyses were performed to identify factors significantly associated with OAC prescription. The baseline variables were compared between patients with and without OAC prescription. The variables with a $p$-value $<0.1$ were included univariate and multivariate logistic regression analysis. All statistical analyses were performed using SPSS Statistics version 20 (SPSS, Inc., Chicago, IL, USA). A $p$-value $<0.05$ was considered statistically significant.

\section{Results}

Of the 3,461 patients enrolled in the COOL-AF Thailand registry, $557(16.1 \%)$ had a history of significant CAD. Among those patients, 253 (45.4\%) had a history of angina pectoris, and 283 (50.8\%) had a history of MI or unstable angina. Two hundred and fifty-six (46.0\%) patients underwent PCI. Among those, 42 (16.4\%) patients received a drug-eluting stent (DES) within one year, and the mean duration from the date of stent implantation was $154.1 \pm 96.1$ days. Of those same 256 patients, $163(63.7 \%)$ received either a DES at a time point longer than one year earlier or a bare-metal stent (BMS) at any time point. Patients had a history of prior CABG in 68 cases (12.2\%) (Table 1).

When compared to patients without CAD, patients with CAD were significantly older $(70.0 \pm 9.9$ vs. $66.9 \pm 11.5$ years, $p<0.001)$, were more likely to be men $(66.6 \%$ vs. $56.6 \%, p<0.001)$, had a higher mean $\mathrm{CHA}_{2} \mathrm{DS}_{2}$-VASc score $(4.17 \pm 1.53$ vs. $2.78 \pm 1.60$, $p<0.001)$, and had a higher mean HAS-BLED score $(2.01 \pm 1.01$ vs. $1.45 \pm 0.98, p<0.001)$. Even though only 2,027 from 2904 patients without CAD (69.8\%) had a non-gender $\mathrm{CHA}_{2} \mathrm{DS}_{2}$-VASc score of 2 or more, almost all patients (537 from 557, 96.4\%) with CAD had a nongender $\mathrm{CHA}_{2} \mathrm{DS}_{2}$-VASc score of 2 or more. When one point was deducted from the HAD-BLED score for use of antiplatelets, that score was still significantly higher in the CAD group, but the difference between groups was markedly reduced $(1.43 \pm 0.90$ vs. $1.24 \pm 0.96, p<0.001)$ (Table 2).
Table 1 Clinical presentation of coronary artery disease in patients with atrial fibrillation

\begin{tabular}{ll}
\hline $\mathbf{C A D}(\mathbf{n}=\mathbf{5 5 7})$ & $\mathbf{n}(\%)$ \\
\hline History of angina pectoris & $253(45.4 \%)$ \\
History of MI/unstable angina & $283(50.8 \%)$ \\
Duration within 1 year & $70(24.7 \%)$ \\
History of PCl & $256(46.0 \%)$ \\
DES within 1 year & $42(16.4 \%)$ \\
DES longer than 1 year and/or BMS (any) & $163(63.7 \%)$ \\
History of CABG & $68(12.2 \%)$ \\
CABG within 1 year & $10(1.8 \%)$ \\
\hline
\end{tabular}

$\mathrm{CAD}$, coronary artery disease; $\mathrm{MI}$, myocardial infarction; $\mathrm{PCl}$, percutaneous coronary intervention; $\mathrm{DES}$, drug-eluting stent; $\mathrm{CABG}$, coronary artery bypass graft surgery

CAD patients had more comorbidities than nonCAD patients, and this was reflected in a higher $\mathrm{CHA}_{2} \mathrm{DS}_{2}$-VASc score among CAD patients. The CAD group had more heart failure (HF) $(39.0 \%$ vs. $24.3 \%$, $p<0.001)$, more HT $(74.7 \%$ vs. $67.1 \%, p<0.001)$, more DM (36.8\% vs. $22.2 \%, p<0.001)$, more peripheral artery disease (PAD) $(3.1 \% v s .1 .0 \%, p<0.001)$, more moderate to severe chronic kidney disease (CKD) $(65.7 \%$ vs. $51.2 \%$ $p<0.001)$, and they had more implantation of a cardiovascular implantable electronic device (CIED) (14.7\% vs. $9.1 \%, p<0.001)$. However, history of stroke and/or transient ischemic attack (TIA) $(14.5 \% v s .17 .9 \%, p=0.053)$ and prior bleeding $(22.7 \%$ vs. $21.8 \%, p=0.865)$ were not significantly different between the CAD and non-CAD groups.

Among all patients enrolled in the registry, patients with CAD ware taking more antiplatelets than patients without CAD $(57.1 \%$ vs. $20.3 \%, p<0.001)$. However, the rate of OAC use was not significantly different between groups $(75.9 \%$ vs. $75.2 \%, p=0.699)$. The majority of patients in both groups used warfarin as an OAC $(91.0 \%$ vs. $91.2 \%, p>0.05$ ) (Table 3).

\section{OAC prescription in patients with and without CAD}

Although use of OAC was not significantly different among overall patients compared between those with and without CAD, OAC use in patients with CAD who had more indications for OAC (patients with nongender $\mathrm{CHA}_{2} \mathrm{DS}_{2}$-VASc score of 2 or more) was significantly lower than in patients without $C A D$ who had indication(s) for OAC (76.0\% vs. 84.3\%, $p<0.001)$. This finding was observed in all CAD subpopulation, including patients who never had ACS or who never received any stent $(76.4 \%$ in patients with CAD who never had ACS or stent vs. $84.3 \%$ in patients without CAD, $p=0.009$ ). Use 
Table 2 Baseline characteristics of atrial fibrillation compared between those without and with coronary artery disease

\begin{tabular}{|c|c|c|c|}
\hline Characteristics & CAD $(n=557)$ & No CAD $(n=2904)$ & $p$-value \\
\hline Age (years) & $70.0 \pm 9.9$ & $66.9 \pm 11.5$ & $<0.001$ \\
\hline Age 65-74 & $210(37.7 \%)$ & $902(31.1 \%)$ & 0.002 \\
\hline Age $\geq 75$ & $185(33.2 \%)$ & $813(28.0 \%)$ & 0.013 \\
\hline Male sex & $371(66.6 \%)$ & $1,643(56.6 \%)$ & $<0.001$ \\
\hline Body weight (kg) & $66.3 \pm 13.9$ & $66.1 \pm 14.9$ & 0.763 \\
\hline $\mathrm{BMI}\left(\mathrm{kg} / \mathrm{m}^{2}\right)$ & $25.1 \pm 4.3$ & $25.2 \pm 4.8$ & 0.767 \\
\hline \multicolumn{4}{|l|}{ Type of AF } \\
\hline Paroxysmal AF & $188(33.8 \%)$ & $891(30.7 \%)$ & 0.152 \\
\hline Persistent/permanent AF & $353(63.4 \%)$ & $1,938(66.7 \%)$ & 0.125 \\
\hline $\mathrm{CHA}_{2} \mathrm{DS}_{2}$ VASc score & $4.17 \pm 1.53$ & $2.78 \pm 1.60$ & $<0.001$ \\
\hline Non-gender $\mathrm{CHA}_{2} \mathrm{DS}_{2}$-VASc score & $3.84 \pm 1.41$ & $2.34 \pm 1.48$ & $<0.001$ \\
\hline Non-gender $\mathrm{CHA}_{2} \mathrm{DS}_{2}$-VASc score 0-1 & $20(3.6 \%)$ & $877(30.2 \%)$ & \\
\hline Non-gender $\mathrm{CHA}_{2} \mathrm{DS}_{2}$-VASc score of 2 or more & $537(96.4 \%)$ & 2,027 (69.8\%) & \\
\hline HAS-BLED score & $2.01 \pm 1.01$ & $1.45 \pm 0.98$ & $<0.001$ \\
\hline Non-antiplatelet HAS-BLED score & $1.43 \pm 0.90$ & $1.24 \pm 0.96$ & $<0.001$ \\
\hline \multicolumn{4}{|l|}{ Comorbidities } \\
\hline History of heart failure & $217(39.0 \%)$ & $706(24.3 \%)$ & $<0.001$ \\
\hline NYHA class & & & 0.288 \\
\hline 1 & $58(26.7 \%)$ & $239(33.9 \%)$ & \\
\hline$\|$ & $125(57.6 \%)$ & $371(52.5 \%)$ & \\
\hline III & $23(10.6 \%)$ & $56(7.9 \%)$ & \\
\hline IV & $3(1.4 \%)$ & $9(1.3 \%)$ & \\
\hline LVEF (\%) & $54.4 \pm 17.1$ & $61.0 \pm 14.0$ & $<0.001$ \\
\hline Hypertension & $416(74.7 \%)$ & $1,948(67.1 \%)$ & $<0.001$ \\
\hline Diabetes mellitus & $205(36.8 \%)$ & $645(22.2 \%)$ & $<0.001$ \\
\hline History of TIA/stroke & $81(14.5 \%)$ & $521(17.9 \%)$ & 0.053 \\
\hline PAD & $17(3.1 \%)$ & $28(1.0 \%)$ & $<0.001$ \\
\hline History of major bleeding & $15(22.7 \%)$ & $57(21.8 \%)$ & 0.865 \\
\hline Intracranial hemorrhage & $1(6.7 \%)$ & $18(31.6 \%)$ & 0.096 \\
\hline Gl hemorrhage & $11(73.3 \%)$ & $26(45.6 \%)$ & 0.056 \\
\hline \multicolumn{4}{|l|}{ Chronic kidney disease } \\
\hline $\mathrm{eGFR}(\mathrm{mL} / \mathrm{min})$ & $48.5 \pm 20.0$ & $57.4 \pm 21.2$ & $<0.001$ \\
\hline $\mathrm{GFR}<60 \mathrm{~mL} / \mathrm{min}$ & $333(73.7 \%)$ & $1,254(59.0 \%)$ & $<0.001$ \\
\hline On renal replacement therapy & $17(3.1 \%)$ & $23(0.8 \%)$ & $<0.001$ \\
\hline Chronic liver disease & $13(2.3 \%)$ & $68(2.3 \%)$ & 0.991 \\
\hline Labile INR & $171(30.7 \%)$ & 724 (24.9\%) & 0.004 \\
\hline CIED & $82(14.7 \%)$ & $263(9.1 \%)$ & $<0.001$ \\
\hline Pacemaker & $51(62.2 \%)$ & $222(84.4 \%)$ & $<0.001$ \\
\hline ICD/CRT-D & $31(37.8 \%)$ & $40(15.2 \%)$ & $<0.001$ \\
\hline CRT-P/CRT-D & $9(11.0 \%)$ & $8(3.0 \%)$ & 0.007 \\
\hline
\end{tabular}

Data presented as mean \pm standard deviation or number and percentage

A $p$-value $<0.05$ indicates statistical significance

$\mathrm{CAD}$, coronary artery disease; BMI, body mass index; AF, atrial fibrillation; HAS-BLED, Hypertension, Abnormal liver/renal function, Stroke history, Bleeding history or predisposition, Labile INR, Elderly, Drug/alcohol usage; NYHA, New York Heart Association; LVEF, left ventricular ejection fraction; TIA, transient ischemic attack; PAD, peripheral arterial disease; GI, gastrointestinal; eGFR, estimated glomerular filtration rate; INR, international normalized ratio; CIED, cardiovascular implantable electronic devices; ICD, implantable cardioverter defibrillator; CRT-D, cardiac resynchronization therapy defibrillator; CRT-P, cardiac resynchronization therapy pacemaker 


\begin{tabular}{|c|c|c|c|}
\hline Therapy and medications & $\begin{array}{l}\text { CAD } \\
(n=557)\end{array}$ & $\begin{array}{l}\text { No CAD } \\
(n=2,904)\end{array}$ & $p$-value \\
\hline Antiplatelet use, n (\%) & $318(57.1 \%)$ & $589(20.3 \%)$ & $<0.001$ \\
\hline Single antiplatelet & $245(77.0 \%)$ & $560(95.1 \%)$ & \\
\hline ASA & $195(79.6 \%)$ & $506(90.4 \%)$ & \\
\hline P2Y12 inhibitors & $50(20.4 \%)$ & $54(9.6 \%)$ & \\
\hline Dual antiplatelet & $73(23.0 \%)$ & $26(4.4 \%)$ & \\
\hline Oral anticoagulants, $n(\%)$ & $423(75.9 \%)$ & $2,183(75.2 \%)$ & 0.699 \\
\hline Warfarin & $385(91.0 \%)$ & $1,991(91.2 \%)$ & \\
\hline NOACs & $38(9.0 \%)$ & $192(8.8 \%)$ & \\
\hline \multicolumn{4}{|c|}{ Rate and rhythm control medications, n (\%) } \\
\hline Beta blocker & $430(77.2 \%)$ & $1,994(68.7 \%)$ & $<0.001$ \\
\hline Diltiazem & $11(2.0 \%)$ & $72(2.5 \%)$ & 0.476 \\
\hline Verapamil & $4(0.7 \%)$ & $29(1.0 \%)$ & 0.533 \\
\hline Digoxin & $66(11.8 \%)$ & $477(16.4 \%)$ & 0.007 \\
\hline Amiodarone & $40(7.2 \%)$ & $259(8.9 \%)$ & 0.181 \\
\hline Other AAD & $5(0.9 \%)$ & $79(2.7 \%)$ & 0.010 \\
\hline \multicolumn{4}{|l|}{ Other medications, n (\%) } \\
\hline DHP-CCB & $130(23.3 \%)$ & 727 (25.0\%) & 0.396 \\
\hline PPI & $194(34.8 \%)$ & $523(18.0 \%)$ & $<0.001$ \\
\hline Statin & $471(84.6 \%)$ & 1,572 (54.1\%) & $<0.001$ \\
\hline ACEI & $158(28.4 \%)$ & $616(21.2 \%)$ & $<0.001$ \\
\hline ARB & 172 (30.9\%) & 648 (22.3\%) & $<0.001$ \\
\hline
\end{tabular}

Data presented as number and percentage

A $p$-value $<0.05$ indicates statistical significance

CAD, coronary artery disease; ASA, aspirin; NOACs, non-vitamin $\mathrm{K}$ antagonist oral anticoagulants; $A A D$, antiarrhythmic drug; $D H P-C C B$, dihydropyridine calcium channel blocker; $\mathrm{PPI}$, proton pump inhibitor; $\mathrm{ACEl}$, angiotensin-converting enzyme inhibitor; ARB, angiotensin receptor blocker

of OAC was lowest in patients who received a DES within 1 year $(65.9 \%)$ (Fig. 1 and Table 4 ).

Univariate and multivariate analysis for factors significantly and/or independently associated with OAC prescription is shown in Table 5 . The variables in the table were selected from baseline variables (in Table 2) that had $\mathrm{p}$-value $<0.1$ for the difference between patients with and without OAC prescription. Concurrent antiplatelet therapy showed the strongest association with lower use of OAC. In 2564 patients who had a non-gender $\mathrm{CHA}_{2} \mathrm{DS}_{2}$-VASc score of 2 or more with or without CAD, 1830 of 1909 (95.9\%) patients who took no antiplatelet were taking $\mathrm{OAC}$. In contrast, only 285 of 552 patients (43.7\%) taking at least one antiplatelet were taking OAC (adjusted OR: 0.02, 95\% CI 0.01-0.03, $p<0.001$ ). Patients taking a single antiplatelet and two antiplatelets were taking OAC in $44.2 \%$ and $40.9 \%$ of patients, respectively.

Although CAD was found to be associated with lower use of OAC. However, after adjusting for other factors (especially antiplatelet status), CAD was instead associated with more use of OAC. Another factor independently associated with lower use of OAC was paroxysmal AF (against permanent AF) (adjusted OR: $0.74,95 \%$ CI $0.55-1.00, p=0.048$ ). Factors independently associated with more use of OAC included history of ischemic stroke or TIA (adjusted OR: 1.85, 95\% CI 1.25$2.74, p=0.002$ ), use of beta-blocker (adjusted OR: 1.81 95\% CI 1.32-2.46, $p<0.001$ ), and use of statin (adjusted OR: $1.97,95 \%$ CI 1.43-2.72, $p<0.001$ ) (Table 5).

\section{Additional antiplatelet in patients already taking OAC}

In patients without $\mathrm{CAD}$, an antiplatelet prescription on top of OAC was uncommon (5.5\% for single antiplatelet, and $0.3 \%$ for two antiplatelets). In contrast, up to $37.5 \%$ of patients with any spectra of CAD were taking single antiplatelet, and $8.1 \%$ were taking two antiplatelets [significantly higher than in patients without CAD $(p<0.001)]$. Addition of antiplatelet was even observed in CAD patients without history of ACS or prior PCI with stent $(20.3 \%$ vs. $5.5 \%, p<0.001$ for single antiplatelet, and $4.3 \%$ vs. $0.3 \%, p=0.013$ for two antiplatelets)(Fig. 1 and Table 4).

Among CAD patients who received a DES within the preceding one year, additional antiplatelet regimens were significantly more aggressive than in CAD patients with no history of ACS or PCI with stent [63\% vs. $4.3 \%$ $(p<0.001)$ were taking concomitant dual antiplatelets (so-called triple antithrombotic therapy-TAT), and 25.9\% were taking concomitant single antiplatelet].

After 1 year of PCI, prescription of TAT was significantly reduced $(63.0$ vs. $7.4, p<0.001)$ to a proportion similar to that of CAD patients who never had PCI or ACS (7.4\% vs. 4.3\%, $p=0.071)$. However, a considerable number of patients after 1 year of PCI maintained single antiplatelet addition to OAC when compared to CAD patients who never had PCI or ACS (59.5\% vs. 20.3\%, $p<0.001)$.

Antiplatelet prescription practice was not significantly different between CAD patients who experienced ACS without undergoing $\mathrm{PCI}$ and CAD patients who did experience ACS with no PCI (28.6\% vs. $20.3 \%, p=0.341$ for single antiplatelet therapy, and $3.6 \% v s .4 .3 \%, p=0.564$ for dual antiplatelet therapy).

The rate of OAC use was analyzed according to CAD and antiplatelet status in all patients and in high-risk group defined as CHA2DS2VASc $\geq 2$ in men and $\geq 3$ in women. The proportion of CAD patients in high-risk group was greater than non-high-risk group [537 (20.9\%) vs $20(2.2 \%), \mathrm{p}<0.001]$. The proportion of antiplatelet use was not difference between high-risk and non-high-risk group [655 (25.5\%) vs $252(28.1 \%), \mathrm{p}=0.135]$. The results of rate of OAC use in all patients and in high-risk group according to CAD and antiplatelet use are shown in Fig. 2. There was a significant interaction of the presence 


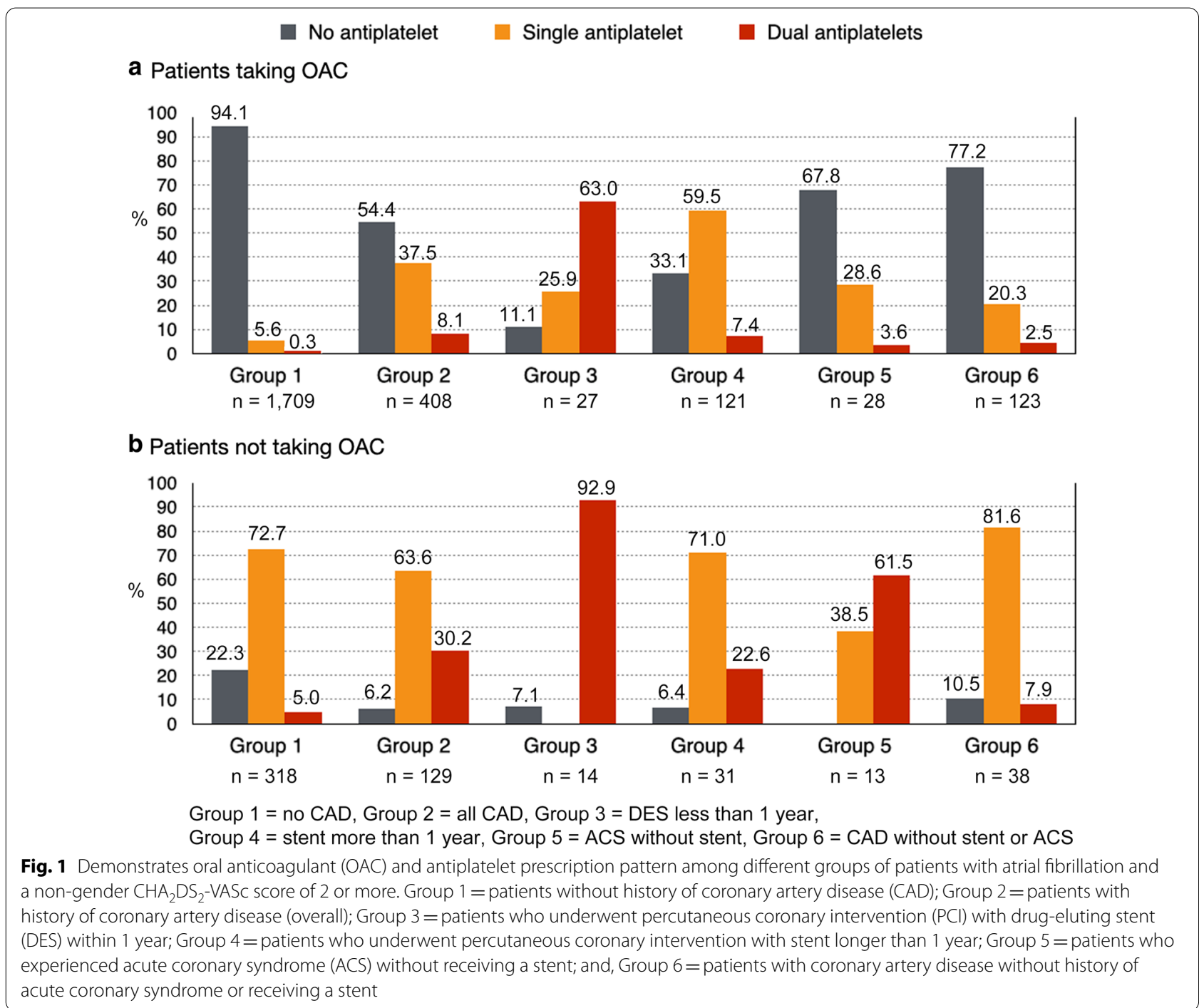

of $\mathrm{CAD}$, and the use of antiplatelet on the rate of OAC use ( $\mathrm{p}$-value for interaction $<0.001$ ). The rate of OAC use is low in patients who use antiplatelet (Fig. 2). Patients with CAD without antiplatelet use had an OR and 95\% CI of OAC use of $3.13(1.59-6.25)(p=0.001)$ compared to patients without CAD and no antiplatelet. However, patients with CAD and antiplatelet use had an OR and $95 \%$ CI of OAC use of $0.19(0.15-0.25)(\mathrm{p}<0.001)$ compared to those without CAD and no antiplatelet. This relation persisted after the adjustment of confounders.

\section{High risk versus low risk of bleeding according to HAS-BLED score}

Patients with $\mathrm{CAD}$ with a $\mathrm{CHA}_{2} \mathrm{DS}_{2}$-VASc score of 2 or more who were taking $\mathrm{OAC}$ were further classified by bleeding risk into high risk (3 or more points) or low risk (0-2 points) according to their HAS-BLED score. In this setting, a point for use of antiplatelet was deducted from their HAS-BLED score to improve the physician's decision whether or not to prescribe antiplatelet. The results showed no significant difference in antiplatelet prescription between the high and low bleeding risk groups (Table 6).

\section{Discussion}

CAD is a common comorbidity in patients with AF. The prevalence of CAD in AF patients ranged from 16.6 to $36.5 \%$ according to the definition of CAD [18-21]. The results of this study showed a prevalence of CAD of $16.1 \%$ in Thai patients with AF. Patients with CAD were older and had more other comorbidities, including $\mathrm{HT}, \mathrm{DM}, \mathrm{HF}, \mathrm{PAD}$, and CKD. Therefore, in addition to $\mathrm{CAD}$ patients being at greater risk for stroke and systemic embolism, they also have more comorbidities 
Table 4 Statistical analysis of data from Fig. 1

\begin{tabular}{|c|c|c|c|c|c|c|}
\hline & $\begin{array}{l}\text { Gr } 1 \text { versus Gr } 2 \\
\text { ( } p \text {-value) }\end{array}$ & $\begin{array}{l}\text { Gr } 1 \text { versus Gr } 6 \\
\text { ( } p \text {-value) }\end{array}$ & $\begin{array}{l}\text { Gr } 3 \text { versus Gr } 4 \\
\text { ( } p \text {-value) }\end{array}$ & $\begin{array}{l}\text { Gr } 3 \text { versus Gr } 6 \\
\text { ( } p \text {-value) }\end{array}$ & $\begin{array}{l}\text { Gr } 4 \text { versus Gr } 6 \\
\text { ( } p \text {-value) }\end{array}$ & $\begin{array}{l}\text { Gr } 5 \text { versus Gr } 6 \\
\text { ( } p \text {-value) }\end{array}$ \\
\hline Rate of OAC & $\begin{array}{l}84.3 \text { vs. } 76.0 \\
<\mathbf{0 . 0 0 1}\end{array}$ & $\begin{array}{l}84.3 \text { vs. } 76.4 \\
\mathbf{0 . 0 0 9}\end{array}$ & $\begin{array}{l}65.9 \text { vs. } 79.6 \\
0.065\end{array}$ & $\begin{array}{l}65.9 \text { vs. } 76.4 \\
0.168\end{array}$ & $\begin{array}{l}79.6 \text { vs. } 76.4 \\
0.494\end{array}$ & $\begin{array}{l}68.3 \text { vs. } 76.4 \\
0.286\end{array}$ \\
\hline \multicolumn{7}{|l|}{ No OAC } \\
\hline No AP & $\begin{array}{l}22.3 \text { vs. } 6.2 \\
<\mathbf{0 . 0 0 1}\end{array}$ & $\begin{array}{l}22.3 \text { vs. } 10.5 \\
0.092\end{array}$ & $\begin{array}{l}7.1 \text { vs. } 6.5 \\
0.931\end{array}$ & $\begin{array}{l}7.1 \text { vs. } 10.5 \\
0.714\end{array}$ & $\begin{array}{l}6.5 \text { vs. } 10.5 \\
0.684\end{array}$ & -- \\
\hline $1 \mathrm{AP}$ & $\begin{array}{l}72.3 \text { vs. } 63.6 \\
<\mathbf{0 . 0 0 1}\end{array}$ & $\begin{array}{l}72.3 \text { vs. } 81.6 \\
0.223\end{array}$ & -- & -- & $\begin{array}{l}71.0 \text { vs. } 81.6 \\
0.299\end{array}$ & $\begin{array}{l}38.5 \text { vs. } 81.6 \\
\mathbf{0 . 0 1 1}\end{array}$ \\
\hline $2 \mathrm{AP}$ & $\begin{array}{l}5.0 \text { vs. } 30.2 \\
<\mathbf{0 . 0 0 1}\end{array}$ & $\begin{array}{l}5.0 \text { vs. } 7.9 \\
0.441\end{array}$ & $\begin{array}{l}92.9 \text { vs. } 22.6 \\
<\mathbf{0 . 0 0 1}\end{array}$ & $\begin{array}{l}92.9 \text { vs. } 7.9 \\
<\mathbf{0 . 0 0 1}\end{array}$ & $\begin{array}{l}22.6 \text { vs. } 7.9 \\
0.100\end{array}$ & $\begin{array}{l}61.5 \text { vs. } 7.9 \\
<\mathbf{0 . 0 0 1}\end{array}$ \\
\hline \multicolumn{7}{|l|}{ Taking OAC } \\
\hline No AP & $\begin{array}{l}94.1 \text { vs. } 54.4 \\
<\mathbf{0 . 0 0 1}\end{array}$ & $\begin{array}{l}94.1 \text { vs. } 77.2 \\
<\mathbf{0 . 0 0 1}\end{array}$ & $\begin{array}{l}11.1 \text { vs. } 33.1 \\
\mathbf{0 . 0 2 3}\end{array}$ & $\begin{array}{l}11.1 \text { vs. } 77.2 \\
<\mathbf{0 . 0 0 1}\end{array}$ & $\begin{array}{l}33.1 \text { vs. } 77.2 \\
<0.001\end{array}$ & $\begin{array}{l}67.9 \text { vs. } 77.2 \\
0.298\end{array}$ \\
\hline $1 \mathrm{AP}$ & $\begin{array}{l}5.5 \text { vs. } 37.5 \\
<\mathbf{0 . 0 0 1}\end{array}$ & $\begin{array}{l}5.5 \text { vs. } 20.3 \\
<\mathbf{0 . 0 0 1}\end{array}$ & $\begin{array}{l}25.9 \text { vs. } 59.5 \\
\mathbf{0 . 0 0 2}\end{array}$ & $\begin{array}{l}25.9 \text { vs. } 20.3 \\
0.520\end{array}$ & $\begin{array}{l}59.5 \text { vs. } 20.3 \\
<\mathbf{0 . 0 0 1}\end{array}$ & $\begin{array}{l}28.6 \text { vs. } 20.3 \\
0.341\end{array}$ \\
\hline $2 \mathrm{AP}$ & $\begin{array}{l}0.3 \text { vs. } 8.1 \\
<\mathbf{0 . 0 0 1}\end{array}$ & $\begin{array}{l}0.3 \text { vs. } 4.3 \\
\mathbf{0 . 0 1 3}\end{array}$ & $\begin{array}{l}63.0 \text { vs. } 7.4 \\
<0.001\end{array}$ & $\begin{array}{l}63.0 \text { vs. } 4.3 \\
<\mathbf{0 . 0 0 1}\end{array}$ & $\begin{array}{l}7.4 \text { vs. } 4.3 \\
0.071\end{array}$ & $\begin{array}{l}3.6 \text { vs. } 4.3 \\
0.564\end{array}$ \\
\hline
\end{tabular}

A $p$-value $<0.05$ indicates statistical significance

$\mathrm{OAC}$, oral anticoagulant; AP, antiplatelet

Group $1=$ patients without history of coronary artery disease

Group $2=$ patients with history of coronary artery disease (overall)

Group 3 = patients who underwent percutaneous coronary intervention with drug-eluting stent within 1 year

Group 4 = patients who underwent percutaneous coronary intervention with stent longer than 1 year

Group $5=$ patients who experienced acute coronary syndrome without receiving a stent

Group $6=$ patients with coronary artery disease without history of acute coronary syndrome or receiving a stent

Table 5 Univariate and multivariate analysis for factors significantly and independently associated with anticoagulant prescription

\begin{tabular}{|c|c|c|c|c|}
\hline \multirow[t]{2}{*}{ Factors } & \multicolumn{2}{|c|}{ Univariate analysis } & \multicolumn{2}{|c|}{ Multivariate analysis } \\
\hline & OR $(95 \% \mathrm{Cl})$ & $p$ & OR (95\% Cl) & $p$ \\
\hline $\mathrm{BMl}>25 \mathrm{~kg} / \mathrm{m}^{2}$ & $1.23(0.99-1.52)$ & 0.065 & & \\
\hline Paroxysmal AF versus permanent AF & $0.68(0.55-0.84)$ & $<0.001$ & $0.74(0.55-1.00)$ & 0.048 \\
\hline CAD & $0.59(0.47-0.74)$ & $<0.001$ & $2.49(1.76-3.52)$ & $<0.001$ \\
\hline Heart failure & $0.72(0.58-0.89)$ & 0.003 & & \\
\hline Ischemic stroke or TIA & $2.54(1.88-3.43)$ & $<0.001$ & $1.85(1.25-2.74)$ & 0.002 \\
\hline PAD & $0.54(0.28-1.06)$ & 0.072 & & \\
\hline On renal replacement therapy & $0.31(0.16-0.61)$ & 0.001 & & \\
\hline Chronic liver disease & $0.48(0.23-1.02)$ & 0.055 & & \\
\hline Antiplatelet use & $0.03(0.03-0.04)$ & $<0.001$ & $0.02(0.01-0.03)$ & $<0.001$ \\
\hline \multicolumn{5}{|l|}{ Rate and rhythm control medications } \\
\hline Beta-blocker & $1.34(1.08-1.66)$ & 0.008 & $1.81(1.32-2.46)$ & $<0.001$ \\
\hline Proton pump inhibitors & $0.54(0.43-0.67)$ & $<0.001$ & & \\
\hline Statin & $1.29(1.04-1.59)$ & 0.020 & $1.97(1.43-2.72)$ & $<0.001$ \\
\hline ACEI & $1.34(1.04-1.72)$ & 0.024 & & \\
\hline Diuretic & $1.22(0.98-1.52)$ & 0.076 & & \\
\hline
\end{tabular}

A $p$-value $<0.05$ indicates statistical significance

$\mathrm{OR}$, odds ratio; $\mathrm{Cl}$, confidence interval; $\mathrm{BMI}$, body mass index; $\mathrm{AF}$, atrial fibrillation; $\mathrm{CAD}$, coronary artery disease; TIA, transient ischemic attack; $\mathrm{PAD}$, peripheral arterial disease; ACEl, angiotensin-converting enzyme inhibitor 


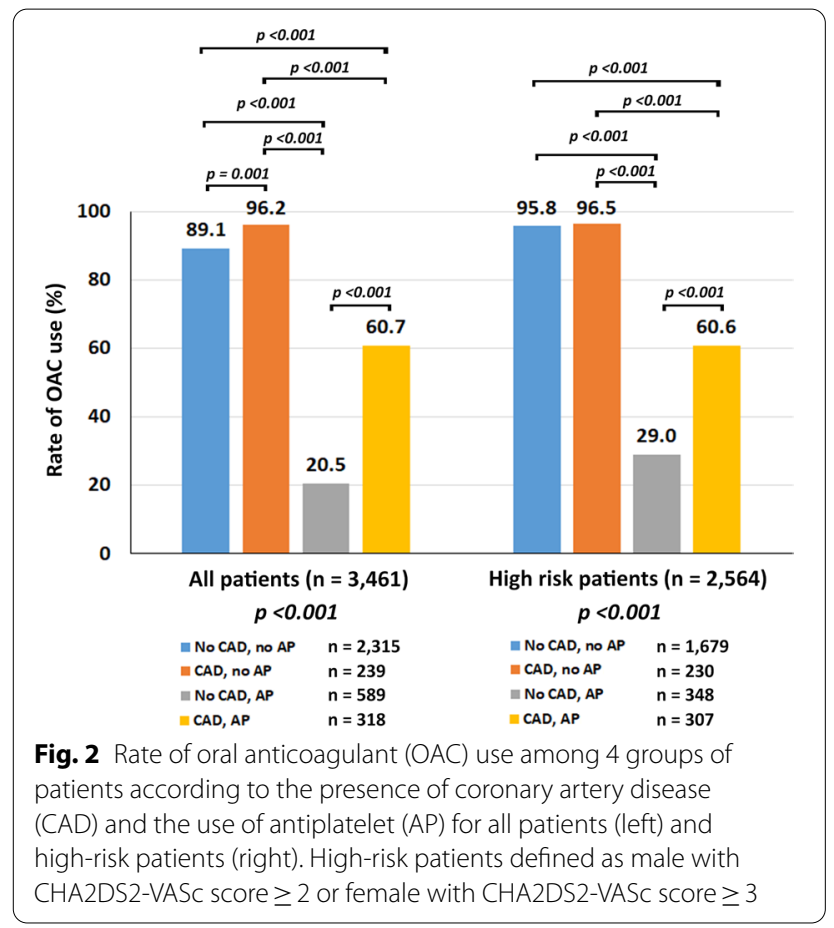

than AF patients without CAD. As a result, almost all patients with coexisting AF and CAD had a non-gender $\mathrm{CHA}_{2} \mathrm{DS}_{2}$-VASc score of 2 or more, and they had an indication for OAC (96.4\%).

Patients with concomitant CAD tend to have a lower time in therapeutic range (TTR). The results of this study showed that TTR was $49.7 \pm 28.3$ in CAD compared to $52.5 \pm 27.3$ for no CAD $(p=0.077)$. Explanations for this finding may include: (1) CAD patients tended to have more comorbidities, which is a predictor of poor INR control, (2) patients with CAD received more proton pump inhibitor, which interacts with warfarin, and (3) physicians might attempt to maintain a lower and narrower INR range (e.g., 2.0-2.5) when antiplatelet is co-administered.

The presence of any spectra of CAD associated with less OAC prescription. The results of this study found that only $76 \%$ of patients with CAD received OAC compared to $84.3 \%$ of patients without CAD when OAC was indicated. Utilization of OAC was lowest (65.9\%) in patients who received a DES within the previous 1 year. In fact, CAD itself associated with more use of OAC according to result of the multivariate analysis because it is one of the risk factors included in the $\mathrm{CHA}_{2} \mathrm{DS}_{2}$-VASc

Table 6 Antiplatelet prescription in patients already using OAC classified by HAS-BLED score

\begin{tabular}{|c|c|c|c|c|}
\hline & \multirow[t]{2}{*}{ Total patients } & \multicolumn{2}{|c|}{ Non-antiplatelet HAS-BLED score } & \multirow[t]{2}{*}{$p$} \\
\hline & & $0-2$ & 3 or more & \\
\hline All CAD, n (\%) & 408 & 353 & 55 & \\
\hline No antiplatelet & $222(54.4 \%)$ & $196(55.5 \%)$ & $26(47.3 \%)$ & 0.253 \\
\hline Single antiplatelet & $153(37.5 \%)$ & $128(36.3 \%)$ & $25(45.5 \%)$ & 0.190 \\
\hline Dual antiplatelets & $33(8.1 \%)$ & $29(8.2 \%)$ & $4(7.3 \%)$ & 1.000 \\
\hline DES $<1$ year, $n(\%)$ & 27 & 23 & 4 & \\
\hline No antiplatelet & $3(11.1 \%)$ & $3(13.0 \%)$ & $0(0.0 \%)$ & 1.000 \\
\hline Single antiplatelet & $7(25.9 \%)$ & $6(26.1 \%)$ & $1(25.0 \%)$ & 1.000 \\
\hline Dual antiplatelets & $17(63.0 \%)$ & $14(60.9 \%)$ & $3(75.0 \%)$ & 1.000 \\
\hline DES > 1 year or BMS for any duration, $n(\%)$ & 125 & 108 & 17 & \\
\hline No antiplatelet & $41(32.8 \%)$ & $35(32.4 \%)$ & $6(35.3 \%)$ & 0.814 \\
\hline Single antiplatelet & $73(58.4 \%)$ & $63(58.3 \%)$ & $10(58.8 \%)$ & 0.970 \\
\hline Dual antiplatelets & $11(8.8 \%)$ & $10(9.3 \%)$ & $1(5.9 \%)$ & 1.000 \\
\hline History of ACS within 1 year, n (\%) & 42 & 33 & 9 & \\
\hline No antiplatelet & $21(50.0 \%)$ & $17(51.5 \%)$ & $4(44.4 \%)$ & 1.000 \\
\hline Single antiplatelet & $12(28.6 \%)$ & $9(27.3 \%)$ & $3(33.3 \%)$ & 0.699 \\
\hline Dual antiplatelets & $9(21.4 \%)$ & $7(21.2 \%)$ & $2(22.2 \%)$ & 1.000 \\
\hline CAD without prior $\mathrm{ACS}$ or $\mathrm{PCl}, \mathrm{n}(\%)$ & 386 & 332 & 54 & \\
\hline No antiplatelet & & $189(56.9 \%)$ & $26(48.1 \%)$ & 0.102 \\
\hline Single antiplatelet & & $115(34.6 \%)$ & $25(46.3 \%)$ & 0.053 \\
\hline Dual antiplatelets & & $28(8.4 \%)$ & $3(5.6 \%)$ & 1.000 \\
\hline
\end{tabular}

A $p$-value $<0.05$ indicates statistical significance

OAC, oral anticoagulant; HAS-BLED, Hypertension, Abnormal liver/renal function, Stroke history, Bleeding history or predisposition, Labile INR, Elderly, Drug/alcohol usage; $\mathrm{CAD}$, coronary artery disease; $\mathrm{DES}$, drug-eluting stent; $\mathrm{BMS}$, bare-metal stent; $\mathrm{ACS}$, acute coronary syndrome; $\mathrm{PCl}$, percutaneous coronary intervention 
score. However, use of antiplatelet was found to be the strongest factor discouraging physicians from prescribing $\mathrm{OAC}$, and $\mathrm{CAD}$ patients are associated with use of antiplatelets.

In this study, the use of dual antiplatelet therapy on top OAC (so-called triple antithrombotic therapy) in patients who underwent PCI with DES within the previous 1 year was very common (63.0\%). By and during the registry's enrollment period, several studies had already been published that reported data that support the use of only one antiplatelet on top $\mathrm{OAC}$ in patients with AF who underwent recent PCI. The What is the Optimal antiplatElet and anticoagulant therapy in patients with oral anticoagulation and coronary StenTing (WOEST) study was an open-label, randomized controlled study that included 573 patients who underwent PCI and who were taking oral anticoagulant. Use of clopidogrel without aspirin caused $64 \%$ less bleeding events, and no significant increase in the rate of thrombotic episodes [6]. A metaanalysis of RCTs and adjusted observational studies that included 4,318 patients with various indications for OAC showed $21.0 \%$ less bleeding with no increase in combined death, MI, stroke, or stent thrombosis [22]. More recent studies in NOACs showed similar results [7-10]. However, taking DAPT without OAC led to $44.0 \%$ more thromboembolic events in patients with AF when compared to AF taking OAC alone [23]. Despite this growing evidence, the prescription pattern from this study indicates that physicians tended to give priority to dual antiplatelet therapy rather than oral anticoagulant. This may result in increased use of triple therapy, which can increase bleeding risk, and increased use of DAPT without $\mathrm{OAC}$, which can increase the risk of stroke.

Recent guidelines also encourage physicians to prescribe OAC without additional antiplatelet in patients who underwent PCI with stent earlier than one year previously. Physicians in this study were more likely to continue at least one antiplatelet together with OAC in more than a half of this subpopulation. The Optimizing Antithrombotic Care in Patients with Atrial Fibrillation and Coronary Stent (OAC-ALONE) study was an open-label, non-inferiority study that compared OAC alone to OAC with antiplatelet. Three-quarters of the study population were taking warfarin, and the rest were taking NOACs. That study was underpowered by premature termination of enrollment and failed to prove non-inferiority [24]. The recently published Atrial Fibrillation and Ischemic events with Rivaroxaban in patiEnts with stable coronary artery disease (AFIRE) study was an another open-label study that compared rivaroxaban 15 or $10 \mathrm{mg}$ alone to rivaroxaban 15 or $10 \mathrm{mg}$ plus one antiplatelet agent. That study included 2236 patients who had history of either CABG or PCI within the previous
1 year. Rivaroxaban monotherapy was found to be superior to combination therapy for both the primary efficacy endpoint (composite of stroke, systemic embolism, MI, unstable angina requiring revascularization, or death from any cause) and the primary safety endpoint (major bleeding) [12]. More data may be needed to convince physicians to discontinue antiplatelet in this scenario.

The HAS-BLED score was introduced in the European Society of Cardiology (ESC) guideline in 2010 [25]. A high HAS-BLED score itself is not a contraindication for OAC, but it helps physicians to focus on modifiable bleeding risk, including unnecessary addition of antiplatelet. More recent guidelines and consensus opinions use the HAS-BLED score to help individualize antithrombotic regimen when concomitant use of antiplatelet is needed. The results of this study showed no significant association between HAS-BLED score and choice of antithrombotic regimen. This finding suggests that physicians may be more concerned about stent complications than bleeding risk. However, there might be unmeasurable patient characteristics that contribute to a physician's decision to discontinue antiplatelet when OAC is needed.

Based on the results of this study, future research should focus on the use of OAC and antiplatelet according to the standard practice guidelines $[3,13,26]$. In stable CAD patients with AF, OAC should be used without antiplatelet. However, in AF patients with recent ACS or PCI, triple therapy should be used for a short duration followed by OAC plus single antiplatelet for up to 12 months.

\section{Limitations}

First, although the COOL-AF Thailand was a prospective cohort, for this study, patient baseline characteristics were collected from data in the medical record and from patient interview. As such, there is a small, but possible chance of some missing data. Second, details specific to the placement of drug-eluting stents and the complexity of coronary lesions in patients who underwent PCI were not collected. Third, antithrombotic regimen pattern data were collected at a time of enrollment. However, the exact duration of each antithrombotic regimen after ACS or PCI could not be assessed. It is also possible that the regimen was more aggressive before the time of enrollment. Lastly, the majority of OAC in this study was warfarin. The major reason for the high rate of warfarin use in the current study is that warfarin is a much more affordable medication compared more contemporary and expensive medications like NOACs. In Thailand, warfarin is promoted as the first choice of OAC among the national healthcare coverage schemes. To use NOACs, physicians need to submit a Drug Utilization Evaluation 
(DUE) form with a good reason for their use in that patient.

\section{Conclusion}

Utilization of oral anticoagulant was less in patients with CAD compared to those without CAD. Use of antiplatelet is the strongest factor associated with non-prescription of OAC. A significant proportion of patients received antiplatelet combined with OAC without indication. Under use of OAC may increase the risk of ischemic stroke, and the inappropriate combination of OAC and antiplatelet may increase the risk of bleeding.

\begin{abstract}
Abbreviations
AAD: Antiarrhythmic drug; ACEl: Angiotensin-converting enzyme inhibitor; AF: Atrial fibrillation; ARB: Angiotensin receptor blocker; ASA: Aspirin; BMI: Body mass index; $C A B G$ : Coronary artery bypass graft surgery; $C A D$ : Coronary artery disease; CIED: Cardiovascular implantable electronic device; CRT-D: Cardiac resynchronization therapy defibrillator; CRT-P: Cardiac resynchronization therapy pacemaker; DES: Drug-eluting stent; DHP-CCB: Dihydropyridine calcium channel blocker; eGFR: Estimated glomerular filtration rate; Gl: Gastrointestinal; ICD: Implantable cardioverter defibrillator; INR: International normalized ratio; MI: Myocardial infarction; NOACs: Non-vitamin K antagonist oral anticoagulants; NYHA: New York Heart Association; PAD: Peripheral arterial disease; PCl: Percutaneous coronary intervention; PPI: Proton pump inhibitor; SD: Standard deviation; TIA: Transient ischemic attack.
\end{abstract}

\section{Acknowledgements}

The authors gratefully acknowledge the patients that agreed to enrollment in the COOL-AF Thailand registry, and Chulalak Komoltri for assistance with statistical analysis.

\section{Authors' contributions}

AW-concept and design, data acquisition, interpretation of data, manuscript preparation, manuscript revision, and manuscript review; RK-concept and design, data acquisition, interpretation of data, manuscript revision, and manuscript review; PK, AY_concept and design, data acquisition, manuscript revision, and manuscript review. All authors read and approved the final manuscript.

\section{Funding}

This study was funded by the Health Systems Research Institute (HSRI) (Grant No. 59-053), and the Heart Association of Thailand under the Royal Patronage of H.M. the King. Neither of the two funding sources influenced any aspect of this study or the authors' decision to submit this manuscript for publication.

\section{Availability of data and materials}

The dataset that was used to support the conclusion of this study is included within the manuscript. Any other additional data will be made available upon request to Rungroj Krittayaphong (rungroj.kri@mahidol.ac.th).

\section{Ethics approval and consent to participate}

The study protocol was approved by the institutional review boards of all participating hospitals. The protocol for this registry was approved by the Central Research Ethics Committee (CREC) for Research in Human Subjects of the Ministry of Public Health, Thailand. Written informed consent was obtained from all included patients prior to participation in accordance with relevant guidelines and regulations.

\section{Consent for publication}

Not applicable.

\section{Competing interests}

None.
Received: 25 October 2020 Accepted: 18 February 2021

Published online: 02 March 2021

\section{References}

1. Kirchhof P, Benussi S, Kotecha D, Ahlsson A, Atar D, Casadei B, et al. 2016 ESC Guidelines for the management of atrial fibrillation developed in collaboration with EACTS. Eur Heart J. 2016;37:2893-962.

2. Hart RG, Pearce LA, Aguilar MI. Meta-analysis: antithrombotic therapy to prevent stroke in patients who have nonvalvular atrial fibrillation. Ann Intern Med. 2007;146:857-67.

3. January CT, Wann LS, Calkins H, Chen LY, Cigarroa JE, Cleveland JC Jr, et al. 2019 AHA/ACC/HRS focused update of the 2014 AHA/ACC/HRS Guideline for the management of patients with atrial fibrillation: a report of the American College of Cardiology/American Heart Association Task Force on Clinical Practice Guidelines and the Heart Rhythm Society. J Am Coll Cardiol. 2019;74:104-32.

4. Knuuti J, Wijns W, Saraste A, Capodanno D, Barbato E, Funck-Brentano C et al. ESC Guidelines for the diagnosis and management of chronic coronary syndromes. Eur Heart J. 2019.

5. Sorensen R, Hansen ML, Abildstrom SZ, Hvelplund A, Andersson C,

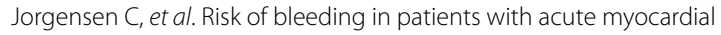
infarction treated with different combinations of aspirin, clopidogrel, and vitamin K antagonists in Denmark: a retrospective analysis of nationwide registry data. Lancet. 2009;374:1967-74.

6. Dewilde WJ, Oirbans T, Verheugt FW, Kelder JC, De Smet BJ, Herrman JP, et al. Use of clopidogrel with or without aspirin in patients taking oral anticoagulant therapy and undergoing percutaneous coronary intervention: an open-label, randomised, controlled trial. Lancet. 2013;381:1107-15.

7. Gibson CM, Mehran R, Bode C, Halperin J, Verheugt FW, Wildgoose P, et al. Prevention of bleeding in patients with atrial fibrillation undergoing $\mathrm{PCl}$. N Engl J Med. 2016;375:2423-34.

8. Cannon CP, Bhatt DL, Oldgren J, Lip GYH, Ellis SG, Kimura T, et al. Dual antithrombotic therapy with Dabigatran after $\mathrm{PCl}$ in atrial fibrillation. N Engl J Med. 2017;377:1513-24.

9. Lopes RD, Vora AN, Liaw D, Granger CB, Darius H, Goodman SG, et al. An open-Label, $2 \times 2$ factorial, randomized controlled trial to evaluate the safety of apixaban vs. vitamin K antagonist and aspirin vs. placebo in patients with atrial fibrillation and acute coronary syndrome and/or percutaneous coronary intervention: rationale and design of the AUGUSTUS trial. Am Heart J. 2018;200:17-23.

10. Vranckx P, Lewalter T, Valgimigli M, Tijssen JG, Reimitz PE, Eckardt L, et al. Evaluation of the safety and efficacy of an edoxaban-based antithrombotic regimen in patients with atrial fibrillation following successful percutaneous coronary intervention (PCI) with stent placement: Rationale and design of the ENTRUST-AF PCI trial. Am Heart J. 2018;196:105-12.

11. Hurlen M, Smith $P$, Arnesen $H$. Effects of warfarin, aspirin and the two combined, on mortality and thromboembolic morbidity after myocardial infarction. The WARIS-II (Warfarin-Aspirin Reinfarction Study) design. Scand Cardiovasc J. 2000;34:168-71.

12. Yasuda S, Kaikita K, Akao M, Ako J, Matoba T, Nakamura M, et al. Antithrombotic therapy for atrial fibrillation with stable coronary disease. N Engl J Med. 2019;381:1103-13.

13. Hindricks G, Potpara T, Dagres N, Arbelo E, Bax JJ, Blomstrom-Lundqvist C et al: 2020 ESC Guidelines for the diagnosis and management of atrial fibrillation developed in collaboration with the European Association of Cardio-Thoracic Surgery (EACTS). Eur Heart J. 2020.

14. Ueki Y, Bar S, Losdat S, Otsuka T, Zanchin C, Zanchin T, et al. Validation of the Academic Research Consortium for High Bleeding Risk (ARC-HBR) criteria in patients undergoing percutaneous coronary intervention and comparison with contemporary bleeding risk scores. Eurolntervention. 2020;16:371-9.

15. Gragnano F, Heg D, Franzone A, McFadden EP, Leonardi S, Piccolo R et al. PRECISE-DAPT score for bleeding risk prediction in patients on dual or single antiplatelet regimens: insights from the GLOBAL LEADERS and GLASSY. Eur Heart J Cardiovasc Pharmacother 2020.

16. Gragnano F, Calabro P, Valgimigli M. Is triple antithrombotic therapy, or rather its duration and composition, the true culprit for the excess of 
bleeding events observed in patients with atrial fibrillation undergoing coronary intervention? Eur Heart J. 2019;40:216-7.

17. Krittayaphong R, Winijkul A, Methavigul K, Wongtheptien W, Wongvipaporn C, Wisaratapong T, et al. Risk profiles and pattern of antithrombotic use in patients with non-valvular atrial fibrillation in Thailand: a multicenter study. BMC Cardiovasc Disord. 2018;18:174.

18. Zelniker TA, Ruff CT, Wiviott SD, Blanc JJ, Cappato R, Nordio F, et al. Edoxaban in atrial fibrillation patients with established coronary artery disease: Insights from ENGAGE AF-TIMI 48. Eur Heart J Acute Cardiovasc Care. 2019;8:176-85.

19. Bahit MC, Lopes RD, Wojdyla DM, Hohnloser SH, Alexander JH, Lewis BS, et al. Apixaban in patients with atrial fibrillation and prior coronary artery disease: insights from the ARISTOTLE trial. Int J Cardiol. 2013;170:215-20.

20. Hohnloser SH, Crijns HJ, van Eickels M, Gaudin C, Page RL, Torp-Pedersen $\mathrm{C}$, et al. Effect of dronedarone on cardiovascular events in atrial fibrillation. N Engl J Med. 2009;360:668-78.

21. Wyse DG, Waldo AL, DiMarco JP, Domanski MJ, Rosenberg Y, Schron EB, et al. A comparison of rate control and rhythm control in patients with atrial fibrillation. N Engl J Med. 2002;347:1825-33.

22. D'Ascenzo F, Taha S, Moretti C, Omede P, Grossomarra W, Persson J, et al. Meta-analysis of randomized controlled trials and adjusted observational results of use of clopidogrel, aspirin, and oral anticoagulants in patients undergoing percutaneous coronary intervention. Am J Cardiol. 2015;115:1185-93.
23. Connolly S, Pogue J, Hart R, Pfeffer M, Hohnloser S, Chrolavicius S, et al. Clopidogrel plus aspirin versus oral anticoagulation for atrial fibrillation in the Atrial fibrillation Clopidogrel Trial with Irbesartan for prevention of Vascular Events (ACTIVE W): a randomised controlled trial. Lancet. 2006;367:1903-12.

24. Matsumura-Nakano Y, Shizuta S, Komasa A, Morimoto T, Masuda $H$, Shiomi H, et al. Open-label randomized trial comparing oral anticoagulation with and without single antiplatelet therapy in patients with atrial fibrillation and stable coronary artery disease beyond 1 year after coronary stent implantation. Circulation. 2019;139:604-16.

25. Camm AJ, Kirchhof P, Lip GY, Schotten U, Savelieva I, Ernst S, et al. Guidelines for the management of atrial fibrillation: the Task Force for the Management of Atrial Fibrillation of the European Society of Cardiology (ESC). Eur Heart J. 2010;31:2369-429.

26. Lip GYH, Banerjee A, Boriani G, Chiang CE, Fargo R, Freedman B, et al. Antithrombotic therapy for atrial fibrillation: CHEST guideline and expert panel report. Chest. 2018;154:1121-201.

\section{Publisher's Note}

Springer Nature remains neutral with regard to jurisdictional claims in published maps and institutional affiliations.
Ready to submit your research? Choose BMC and benefit from:

- fast, convenient online submission

- thorough peer review by experienced researchers in your field

- rapid publication on acceptance

- support for research data, including large and complex data types

- gold Open Access which fosters wider collaboration and increased citations

- maximum visibility for your research: over 100M website views per year

At BMC, research is always in progress.

Learn more biomedcentral.com/submissions 